\title{
Research on Popularization Effect of ,Near-Zero Emissions" of Thermal Power Based on Multi-Scenario Simulation
}

\author{
Yuansheng Huang, Xiaoqian Qi*, Baosheng Zhang \\ Department of Economics and Management, North China Electric Power University, \\ No. 689, Huadian Road, Baoding 071003, China
}

Received: 15 November 2020

Accepted: 24 March 2021

\begin{abstract}
In China's energy consumption, about $50 \%$ of coal is used for power generation conversion, and the resulting environmental impact and air pollution problems cannot be ignored. Therefore, it is of great practical significance to improve the level of clean coal utilization. Based on the background that the country currently grants a subsidy of RMB $0.01 / \mathrm{kWh}$ for the "near-zero emission" of thermal power, this paper applies system dynamics (SD) modeling to simulate the impact of different policy scenarios on the promotion and effects of "near-zero emission" of thermal power. From the perspective of promotion speed and emission reduction contribution, simulation analysis found that thermal power "near-zero emission" technology can bring more significant environmental benefits and has promotion value. The main conclusions are as follows: (1) After 2020, if the current subsidy of RMB 0.01/kWh continues to be implemented, the "near-zero emission" retrofit of stock units can be fully completed in early 2026. (2) Compared with no policy subsidies, the cumulative emission reduction of sulfur dioxide, nitrogen oxides and soot will be approximately 15.13 million tons, 15.13 million tons and 2.37 million tons from the beginning of 2016 to the beginning of 2026, respectively.
\end{abstract}

Keywords: "near-zero emissions" technology promotion effect, system dynamics model, air pollutant emissions, policy subsidies, multi-scenario simulation

\section{Introduction}

In order to promote the "near-zero emission" technology of thermal power quickly and reduce environmental pollution and air pollutant emissions, the National Development and Reform Commission issued

*e-mail: xq.qi.ncepu@outlook.com the "Notice on the Implementation of Coal-fired Power Plant Ultra-low Emissions Electricity Price Support Policy Relevant Issues" (Development and Reform Price [2015] No. 2835), which was decided on $1^{\text {st }}$ January 2016, the state will give a policy subsidy of RMB $0.01 / \mathrm{kWh}$ to coal-fired power generation enterprises whose air pollution emissions reach the "near-zero emission" standard. In recent years, the "near-zero emission" technology of thermal power has attracted extensive attention from scholars. 
Domestic and foreign research on pollutant emissions from coal-fired thermal power plants and "near-zero emission" technologies mainly focus on technology optimization, energy efficiency evaluation, environmental benefits, environmental cost factors, and the need for government regulation, etc. The paper [1] pointed out that coal-fired power plants using "nearzero emission" technology have extremely low air pollutant emissions and energy efficiency has reached a record high level. This technology plays an increasingly important role in solving China's energy and environmental problems. From a technical perspective, the literature [2] has developed a valuable technical approach to eliminate $\mathrm{SO}_{3}$ emissions from power plants burning high-sulfur coal. Research [3] uses the fuzzy comprehensive evaluation method to construct a multiindex comprehensive energy efficiency evaluation system for technology, environmental protection, economic benefits and social benefits.In order to reduce the emissions of volatile organic compounds (VOCs) from coal-fired power plants and achieve ultra-low emissions, the results of the paper [4] show that the use of APCD systems to collaboratively remove VOCs can achieve an ultra-low emission technology with an efficiency of over $80 \%$. Literature [5] discusses the driving factors for the significant decline in air pollutant concentrations and emission factors of coalfired power plants in China from the perspectives of policy formulation, application of removal technologies, tightening of emission standards, technological improvements, monitoring systems and economic measures. The study [6] comprehensively evaluated the mercury control effect and potential cross-media effects of ultra-low emission technologies through field tests, model calculations and literature reviews. Literature [7] discusses a reasonable method to select the most economical desulfurization system transformation plan. In this article [8], a case represented by the coal-fired power generation sector studies the technical solutions and evaluates their cost-effectiveness, thereby providing empirical evidence for the impact of technical synergy on cost-effectiveness and clarifying future pollution control strategies. In the paper [9], the author uses the spatial Dubin model and the extended Cobb-Douglas production function (CD production function) to study the direct, indirect and overall impact of clean energy consumption and element allocation on China's air pollution emissions. In the literature [10], from the perspective of technical and economic factors and limiting PM10 emissions, a complete system dynamics model is established to simulate the evolution path of China's power structure. Secondly, conduct scenario analysis under different growth rates of clean power generation capacity to seek appropriate policy guidance for reducing PM10. Literature [11] established an hourly emission inventory and designed updated emission factors (EFs) for pollutants from coal-fired power plants. The new inventory and updated EF will enable people to better understand the time changes of power plant emissions and reduce the uncertainty caused by the overestimation of EF after the implementation of ultralow emission technologies. The purpose of this article [12] is to establish an evolutionary game for analyzing the diffusion of "near-zero emission" technological innovation in coal-fired power plants. Simulations show that in order to maximize profits, coal-fired power plants should adopt independently developed "near-zero emission" technologies, and increasing subsidy intensity plays an important role in promoting diffusion. Literature [13] aims to explore investment strategies suitable for Chinese power companies under the influence of the National Carbon Emissions Trading (NCET) market. It is also suggested that before establishing the NCET market, companies should prioritize investment in clean technology rather than large-scale installation of green energy. The main goal of this article [14] is to propose a centralized energy management strategy, which focuses on maximizing investment portfolio solutions, including favorable market opportunities, such as continuous intraday markets and frequency recovery reserves. The results of literature [15] show that the resource depletion coefficient of coal-fired power generation is lower than that of gas-fired power generation, and coal-fired power generation should become the main component of China's power generation. At the same time, improving power generation efficiency or shortening transportation distance can effectively improve energy conservation and emission reduction. Since low cost, high reliability and low pollution are the main goals of current unit commitment optimization, the study [16] established a multi-objective unit commitment model based on the above goals. The results of the paper [17] show that the annual release of the policies driving the clean development of coal-fired power generation in China shows a fluctuating growth trend. Among them, policy themes are mainly divided into production capacity management and air pollutant control. The policy measures mainly include the elimination of backward units, project approval standards, power generation price supervision, tax incentives, loan policies, and information disclosure. The paper [18] combines life cycle assessment and life cycle cost calculation methods to analyze and compare the environmental and economic impacts of $315 \mathrm{MW}$ units before and after the ultra-clean emission transformation. After the ultra-clean emission transformation, the environmental impact of $1000 \mathrm{kWh}$ power plant flue gas treatment has been reduced from 0.1529 to 0.1295 . In the study [19], the standardized generation cost method (LGCM) was used to analyze the economics of power plants, and mainly analyzed the control costs related to $\mathrm{CO}_{2}$ and $\mathrm{NO}_{2}$. The literature [20] focuses on the environmental impact of China's thermal power capacity utilization changes on pollutant emissions. Under the econometric strategy of the Panel Smooth Conversion Regression (PSTR) model, the transitional variables of power generation and electricity consumption were used to evaluate the conversion 
mechanism and path of seven pollutant emissions to the utilization of thermal power capacity. The article [21] studies the impact of coal substitution of solid fuels from municipal solid waste using hydrothermal carbonization technology on greenhouse gas and other air pollutant emissions. The South Korean government is seeking natural gas (NG)-based combined heat and power (CHP) power generation to replace part of coalfired power generation to reduce air pollutant emissions. This article [22] attempts to evaluate the willingness to pay (WTP) of the public willing to use contingent valuation $(\mathrm{CV})$ as an alternative. The paper [23] takes a $200 \mathrm{MW}$ circular boiler in a certain power plant as the research object for simulation analysis. Under the condition of the boiler maximum continuous rate (BMCR), the thermal efficiency of the boiler and the emission of nitrogen oxides were compared before and after the transformation.

Through the analysis of pollutant emissions from coal-fired power plants and related literature on "nearzero emission" technology, it is found that few scholars have studied the popularization and environmental effect of "near-zero emission" technology under government intervention. Therefore, the innovative points of the article are the use of system dynamics model to construct a thermal power "near-zero emission" promotion effect model, and also set up a cost-profit subsystem, an investment development subsystem, and an environmental effect subsystem. Finally, we simulated the promotion of "near-zero emission" technology under different policy scenarios, and measured the effect of thermal power air pollutant reduction caused by different policy subsidies. Even this article can provide some reference to the government's rational implementation policies.

\section{Material and Methods}

In this paper, the system dynamics method will be used to build a "near-zero emission" technology promotion model. System Dynamics (SD) is a method of analyzing the structure and behavior of social systems and providing useful information for decision makers. System simulation is to establish a simulation model that can describe the structure or behavior of the system and has a certain logical relationship or mathematical equation based on the analysis of the nature of the elements of the system and the relationship between them according to the purpose of system analysis. Eventually, experiments or quantitative analysis can be performed to obtain all kinds of information needed for correct decision-making [24].

\section{System Dynamics Model Boundary Setting}

The determination of reasonable system boundaries in the system dynamics model is of great significance for studying the dynamic behavior of the system. In this section, the "near-zero emission" promotion effect model of thermal power based on system dynamics is constructed, and the boundary will be set according to three subsystems: cost-profit subsystem, investment development subsystem, and environmental effect subsystem. For the convenience of analysis, the units that implement "near-zero emission" are collectively referred to as x-units, and the units that do not implement "near-zero emission" are collectively referred to as y-units.

1) Cost-profit subsystem. By analyzing the impact of policy subsidies on the cost and profit changes of the $\mathrm{x}$-unit and $\mathrm{y}$-unit, the investment willingness index is output, and the application and promotion of the technology are affected.

2) Investment and development subsystem. Analyze the impact of policy subsidies on capacity changes of $y$-machine assembly machines to reflect the promotion of "near-zero emission" technology. The system is mainly affected by the investment intention of "nearzero emission" and environmental satisfaction.

3) Environmental effect subsystem. The changes in emissions of soot, $\mathrm{SO}_{2}$ and $\mathrm{NO}_{\mathrm{x}}$ are studied, and the satisfaction index of environmental effects is output to influence the investment development subsystem.

From the above analysis, we can see that the three subsystems influence and restrict each other. The operation of each subsystem is not only determined by its internal structure, but also has a great connection with other subsystems. The three subsystems form a closely linked whole, which serves as a system dynamics model for the promotion effect of "near-zero emissions" technology of thermal power.

\section{System Dynamics Model Building}

The system dynamics model of thermal power "nearzero emission" technology promotion effect is divided into cost-profit subsystem, investment development subsystem, and environmental effect subsystem.

The main output indicator of the cost-profit subsystem is the near zero emission investment willingness, which is positively correlated with the annual profit of the $\mathrm{x}$-unit and negatively correlated with the annual profit of the y-unit; the investment development subsystem mainly changes through the installed capacity of the y-unit. The situation reflects the promotion effect of "near-zero emission" technology, which is positively correlated with the increase in the capacity of the y-machine assembly machine and negatively correlated with the decrease in the capacity of the y-machine assembly machine; the main indicators of the environmental effect subsystem research are unit thermal power generation dust, $\mathrm{SO}_{2}$ and $\mathrm{NO}_{x}$ emissions. The relationship between the influencing factors of the three indicators is similar, so we take the unit of thermal power generation dust emission as an example 


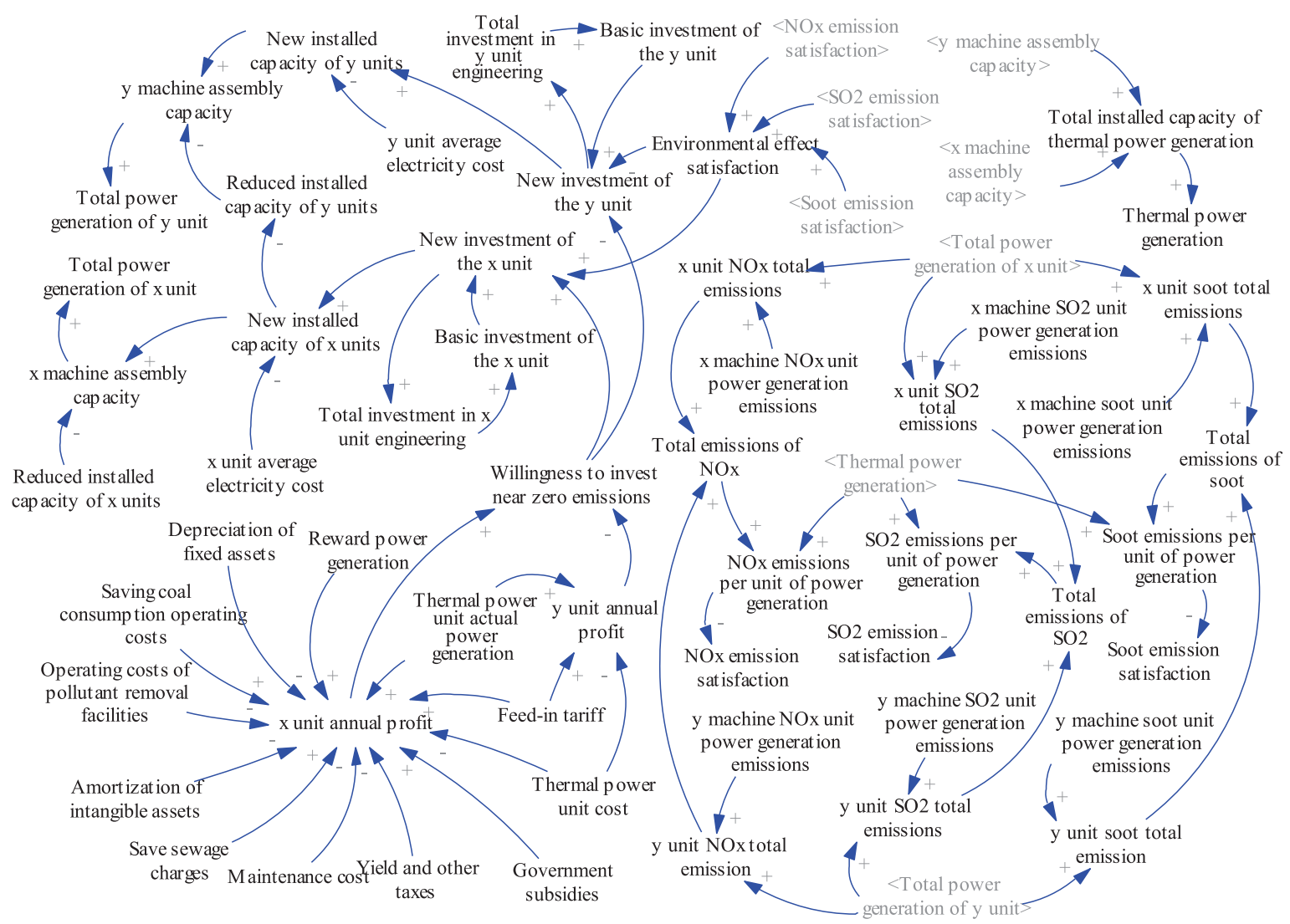

Fig. 1. Causality diagram.

to analyze the causal relationship between variables. This index is positively correlated with the ratio of total smoke and dust emissions to thermal power generation.

In this section, the system boundary has been set and the causal relationship between the key factors affecting the system has been analyzed. Finally, draw a causality diagram of the model, as shown in Fig. 1.

The main output index of the cost-profit subsystem is the willingness to invest in "near-zero emission". The specific quantitative relationship of this index can be referred to formula (1). The calculation of the annual profit of the x-unit is relative to the annual profit of the y-unit, which is mainly affected by factors such as cost changes and government subsidies brought by the "near-zero emissions" transformation. For the specific quantitative relationship, refer to the formula (2) and (3). In the cost-profit subsystem, there are three auxiliary variables: $x$-unit annual profit, $y$ - unit annual profit, and near zero emission investment willingness. And several constants such as government subsidies, actual power generation of thermal power units, on-grid electricity prices, and cost changes caused by the implementation of "near-zero emission".
Willingness to invest near zero emissions

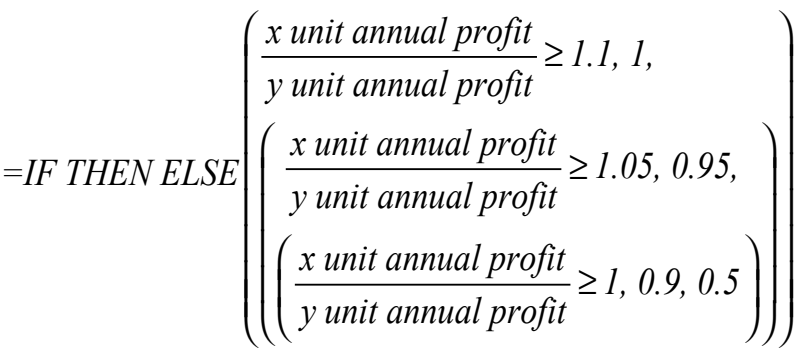

$x$ unit annual profit

$=($ "Feed-in tariff"-Thermal power unit cost+Government subsidies $)$

XThermal power unit actual power generation

-Depreciation of fixed assets-Maintenance cost-Yield and other taxes

-Operating costs of pollutant removal facilities-Amortization of intangible assets

+ Saving sewage charges + Saving coal consumption operating costs

y unit annual profit=("Feed-in tariff"-Thermal power unit cost) $\times$ Thermal power unit actual power generation

The investment development subsystem mainly reflects the promotion effect of the "near-zero emission" technology through the change of the installed capacity 
of the y-unit. This indicator is mainly expressed by the difference between the increase and decrease of the installed capacity. The specific quantitative relationship can refer to the formula (4) and (5). The newly added capacity of the thermal power generator assembly is calculated from the ratio of the unit's new investment per year to the average kilowatt cost. For the specific quantitative relationship, refer to formulas (6) and (7). There are four state variables in the investment and development subsystem, $\mathrm{x}$ machine assembly capacity and y machine assembly capacity. The six rate variables include new installed capacity of $\mathrm{x}$ units, reduced installed capacity of $\mathrm{x}$ units, new installed capacity of $y$ units, reduced installed capacity of y units, new investment of the $\mathrm{x}$ unit, new investment of the $\mathrm{y}$ unit. There are also multiple auxiliary variables such as environmental effect satisfaction, near zero emission investment willingness, and multiple constants such as $\mathrm{x}$-unit average electricity cost and $\mathrm{y}$-unit average electricity cost.

$x$ machine assembly capacity

$=I N T E G$ (New installed capacity of $x$ units-Reduced installed capacity of $x$ units)

y machine assembly capacity

=INTEG (New installed capacity of y units-Reduced installed capacity of y units)

New installed capacity of $x$ units

(Willingness to invest near zero emissions $\times$ Environmental effect satisfaction +1 )

$=\frac{x \text { Fundamental investment in } x \text { unit }}{x \text { unit average electricity cost }}$

New installed capacity of y units

(Willingness to invest near zero emissions $\times$ Environmental effect satisfaction)

$=-\frac{x \text { Fundamental investment in } y \text { unit }}{y \text { unit average electricity cost }}$

The main indicators of the environmental effect subsystem research are the emissions of soot, $\mathrm{SO}_{2}$ and $\mathrm{NO}_{\mathrm{x}}$ per unit of thermal power generation, and ultimately the formation of environmental effect satisfaction affects the promotion of "near-zero emissions" technology. We take the unit dust emission of thermal power generation as an example to analyze the quantitative relationship between its variables, see formulas (8) to (13). The indicator is derived from the ratio of the total smoke emission to the thermal power generation, and the total smoke emission is represented by the sum of the total smoke emission from the $\mathrm{x}$ units and $y$ units. In the environmental effect subsystem, there are mainly several auxiliary variables such as unit thermal power smoke emission, unit thermal power $\mathrm{SO}_{2}$ emission, unit thermal power $\mathrm{NO}_{x}$ emission; smoke emission satisfaction, $\mathrm{SO}_{2}$ emission satisfaction, $\mathrm{NO}_{x}$ emission satisfaction, etc. Multiple constants such as unit thermal power smoke emissions, unit thermal power $\mathrm{SO}_{2}$ emissions, unit thermal power $\mathrm{NO}_{x}$ emissions, etc. The main variables and types of the entire system are shown in Table 1.

\section{Total emissions of soot}

$=x$ unit soot total emissions $+y$ unit soot total emission

Soot emissions of per unit power generation $=\frac{\text { Total emissions of soot }}{\text { National thermal power generation }}$

Soot emission satisfaction

$=$ IF THEN ELSE $\left.\left(\begin{array}{l}\text { Soot emissions of per unit power generation }<0.019,1, \\ \text { Soot emissions of per unit power generation }<0.05,0.95, \\ (\text { Soot emissions of per unit power generation }<0.09,0.9,0.5)\end{array}\right)\right)$

$\mathrm{SO}_{2}$ emission satisfaction

$=I F$ THEN ELSE $\left(\begin{array}{l}\mathrm{SO}_{2} \text { emissions of per unit power generation }<0.136,1, \\ \mathrm{SO}_{2} \text { emissions of per unit power generation }<0.3,0.95, \\ \left(\begin{array}{l}\left.\mathrm{SO}_{2} \text { emissions of per unit power generation }<0.47,0.9,0.5\right)\end{array}\right)\end{array}\right)$

$\mathrm{NO}_{x}$ emission satisfaction

$=$ IF THEN ELSE $\left(\begin{array}{l}N O_{x} \text { emissions of per unit power generation }<0.194,1, \\ \left(\begin{array}{l}N \\ O_{x} \text { emissions of per unit power generation }<0.3,0.95, \\ \left(N O_{x} \text { emissions of per unit power generation }<0.43,0.9,0.5\right)\end{array}\right)\end{array}\right)$

Environmental effect satisfaction

$=\frac{\text { Soot emission satisfaction }+\mathrm{SO}_{2} \text { emission satisfaction }+\mathrm{NO}_{x} \text { emission satisfaction }}{3}$

Based on the above analysis of the causal structure of each subsystem and the analysis of indicator types, we constructed a system dynamics model of the "nearzero emissions" promotion effect in Vensim software. Draw state variables, rate variables, auxiliary variables and constants corresponding to the causality diagram and variable types, and convert each variable in the model into the symbol form of the flow chart, as shown in Fig. 2. 
Table 1. Model main indicators and types.

\begin{tabular}{|c|c|c|c|c|c|}
\hline Variable & Unit & Species & Variable & Unit & Species \\
\hline $\mathrm{x}$ unit annual profit & $\mathrm{CNY}^{*}$ & Auxiliary variable & $\begin{array}{l}\text { Operating costs of pollutant } \\
\text { removal facilities }\end{array}$ & $\mathrm{CNY}^{*}$ & Constant \\
\hline y unit annual profit & $\mathrm{CNY}^{*}$ & Auxiliary variable & Yield and other taxes & $\mathrm{CNY}^{*}$ & Constant \\
\hline $\begin{array}{l}\text { Willingness to invest near zero } \\
\text { emissions }\end{array}$ & Dmnl & Auxiliary variable & Maintenance cost & $\mathrm{CNY}^{*}$ & Constant \\
\hline Thermal power unit cost & $\mathrm{CNY}^{*}$ & Constant & $\begin{array}{l}\text { Saving coal consumption } \\
\text { operating costs }\end{array}$ & $\mathrm{CNY}^{*}$ & Constant \\
\hline $\begin{array}{c}\text { Thermal power unit actual power } \\
\text { generation }\end{array}$ & MWh & Constant & $\begin{array}{c}\text { Amortization of intangible } \\
\text { assets }\end{array}$ & $\mathrm{CNY}^{*}$ & Constant \\
\hline Feed-in tariff & $\mathrm{CNY}^{*}$ & Constant & Save sewage charges & $\mathrm{CNY}^{*}$ & Constant \\
\hline Reward power generation & MWh & Constant & Government subsidies & $\mathrm{CNY}^{*}$ & Constant \\
\hline Depreciation of fixed assets & $\mathrm{CNY}^{*}$ & Constant & $\mathrm{y}$ unit reduction rate & Dmnl & Constant \\
\hline $\mathrm{x}$ machine assembly capacity & MW & State variables & y unit average electricity cost & $\mathrm{CNY}^{*}$ & Constant \\
\hline y machine assembly capacity & MW & State variables & $\mathrm{x}$ unit new investment & $\mathrm{CNY}^{*}$ & Rate variable \\
\hline $\begin{array}{l}\text { Reduced installed capacity of } x \\
\text { units }\end{array}$ & MW & Rate variable & y unit new investment & $\mathrm{CNY}^{*}$ & Rate variable \\
\hline $\begin{array}{l}\text { Reduced installed capacity of y } \\
\text { units }\end{array}$ & MW & Rate variable & $\mathrm{x}$ unit basic investment & $\mathrm{CNY}^{*}$ & Auxiliary variable \\
\hline New installed capacity of $x$ units & MW & Rate variable & y unit basic investment & $\mathrm{CNY}^{*}$ & Auxiliary variable \\
\hline New installed capacity of y units & MW & Rate variable & $\mathrm{x}$ unit reduction rate & Dmnl & Constant \\
\hline $\mathrm{x}$ unit average electricity cost & $\mathrm{CNY}^{*}$ & Constant & $\begin{array}{l}\text { Environmental effect } \\
\text { satisfaction }\end{array}$ & Dmnl & Auxiliary variable \\
\hline Total emissions of soot & $\mathrm{kg}$ & Auxiliary variable & y unit total soot emission & $\mathrm{kg}$ & Auxiliary variable \\
\hline Unit thermal power soot emission & $\mathrm{kg} / \mathrm{MWh}$ & Auxiliary variable & $\mathrm{y}$ unit total $\mathrm{SO}_{2}$ emission & $\mathrm{kg}$ & Auxiliary variable \\
\hline Total emissions of $\mathrm{SO}_{2}$ & $\mathrm{~kg}$ & Auxiliary variable & $\mathrm{y}$ unit total $\mathrm{NO}_{\mathrm{x}}$ emission & $\mathrm{kg}$ & Auxiliary variable \\
\hline Unit thermal power $\mathrm{SO}_{2}$ emission & $\mathrm{kg} / \mathrm{MWh}$ & Auxiliary variable & $\mathrm{x}$ unit total soot emission & $\mathrm{kg}$ & Auxiliary variable \\
\hline Total emissions of $\mathrm{NO}_{\mathrm{x}}$ & $\mathrm{kg}$ & Auxiliary variable & $\mathrm{x}$ unit total $\mathrm{SO}_{2}$ emission & $\mathrm{kg}$ & Auxiliary variable \\
\hline Unit thermal power $\mathrm{NO}_{x}$ emission & $\mathrm{kg} / \mathrm{MWh}$ & Auxiliary variable & $\mathrm{x}$ unit total $\mathrm{NO}_{\mathrm{x}}$ emission & $\mathrm{kg}$ & Auxiliary variable \\
\hline $\mathrm{x}$ machine unit soot emission & $\mathrm{kg} / \mathrm{MWh}$ & Constant & Soot emission satisfaction & Dmnl & Auxiliary variable \\
\hline $\mathrm{x}$ machine unit $\mathrm{SO}_{2}$ emission & $\mathrm{kg} / \mathrm{MWh}$ & Constant & $\mathrm{SO}_{2}$ emission satisfaction & Dmnl & Auxiliary variable \\
\hline $\mathrm{x}$ machine unit $\mathrm{NO}_{\mathrm{x}}$ emission & $\mathrm{kg} / \mathrm{MWh}$ & Constant & $\mathrm{NO}_{\mathrm{x}}$ emission satisfaction & Dmnl & Auxiliary variable \\
\hline National Thermal Power Generation & MWh & $\begin{array}{l}\text { Auxiliary } \\
\text { variable }\end{array}$ & Total installed thermal power & MW & Auxiliary variable \\
\hline
\end{tabular}

* The CNY in the table is Ten thousand yuan

\section{Parameter Description and Model Validity Test}

The promotion of "near-zero emissions" involves many factors such as the socio-economic and social environment, and the complexity is relatively high. In this section, we ideally set the "near-zero emissions" promotion system, abstract the complex problems in reality and use the system dynamics method to construct the "near-zero emissions" promotion effect model. Before simulating the model, we must first explain the source of the parameters of the model, and secondly, we must verify the effectiveness of the system, which is a link that the system dynamics method must carry out.

1) The data sources used in this model are mainly from authoritative data published by China Statistical Yearbook, China Environmental Statistics Yearbook, National Bureau of Statistics, etc. Some data also refer to relevant literature [25] and relevant research reports and empirical values. In this model, the start time of the system simulation time is set to 2016, the time step is 1 year, and the end time is 2026 years. Since the "near-zero emission" policy subsidies for thermal 




Fig. 2. Flow chart of system dynamics of "near-zero emission" promotion effect.

power will be implemented from January 1, 2016, in order to maintain synchronization, we will use the data at the end of 2015 as the starting data at the beginning of 2016 , so the annual simulation data refers to the beginning of the year data.

2) The reason why the system dynamics method can run is that the model test is very important. The model is constructed reasonably and can reflect the actual situation of the system. The predicted trend simulated will be reasonable, otherwise the simulated results of the model will be unreliable. Therefore, the effectiveness of the system must be tested, which is a link that the system dynamics method must carry out. The validity test is mainly divided into two aspects: runtime structural test and behavior consistency test.
First of all, before the system runs simulation, the constructed system dynamics model is tested in the software, which can test the setting of the boundary, the causality loop, the setting of variables, the rationality of the flow diagram and the equation, etc. So as to confirm that the establishment of the model basically meets the requirements of the system dynamics method. Both tests in this model have shown OK as shown in Fig. 3, that is, the structural test of the model is reasonable.

Secondly, test the model behavior consistency. The data formed by the simulation is compared to historical existing data, and the behavioral consistency of the model is verified by calculating the error rate of the data. This paper reflects the "near-zero emissions" technology promotion through the thermal power

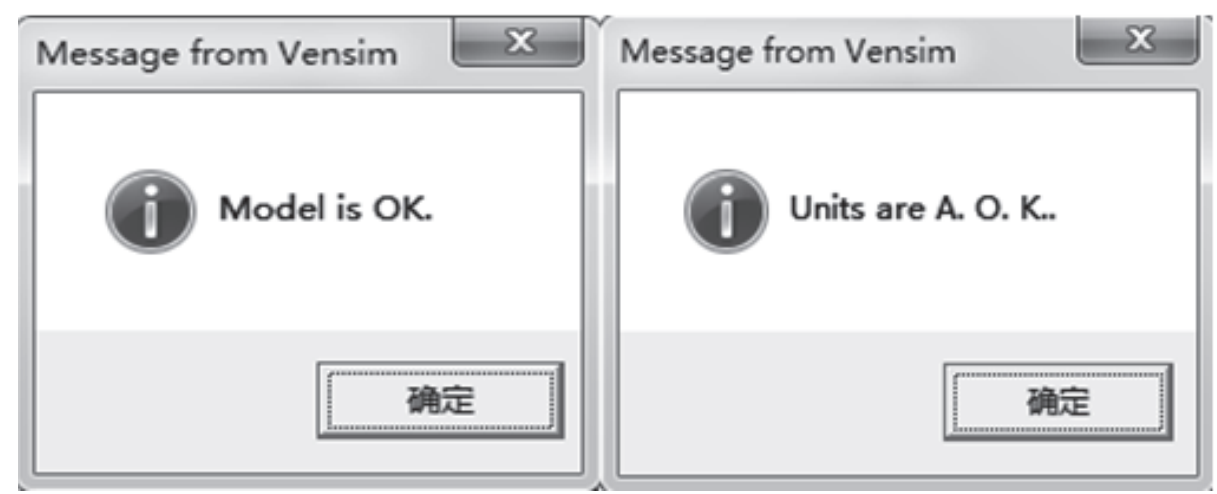

Fig. 3. Structural verification of the model. 
Table 2. Data error calculation table.

\begin{tabular}{|c|c|c|c|c|c|}
\hline Variable & Numeric type & 2016 & 2017 & 2018 & 2019 \\
\hline \multirow{2}{*}{$\begin{array}{c}\text { Total installed } \\
\text { capacity of thermal } \\
\text { power }(\mathrm{MW})\end{array}$} & Historical value & 1060944 & 1104950 & 1143670 & 1190550 \\
\cline { 2 - 6 } & Simulation value & 987960 & 986893 & 1002590 & 1036670 \\
\cline { 2 - 6 } & Error rate & 0.069 & 0.107 & 0.123 & 0.129 \\
\hline
\end{tabular}

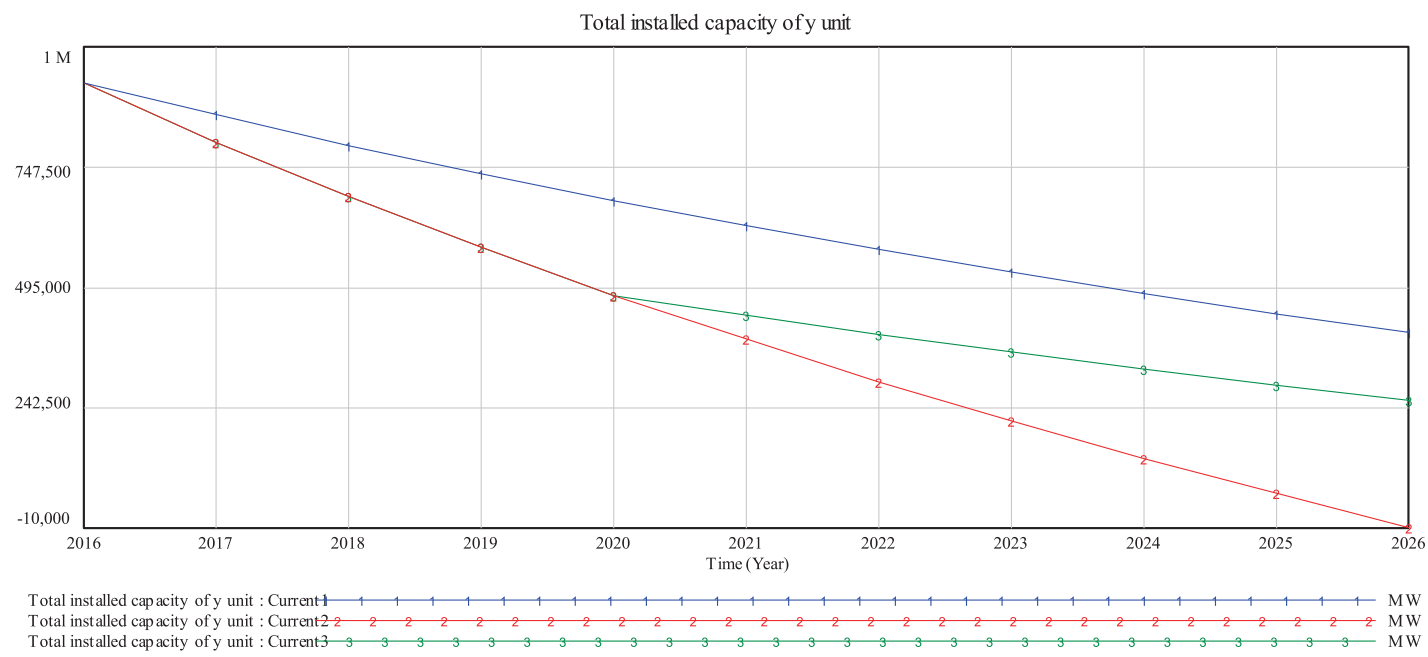

Fig. 4. Scenario simulation comparisonof total installed capacity of y unit.

installed capacity, so the variable of the total amount of thermal power installed is selected. Next, the historical data and analog data of the total amount of thermal power installed in 2016-2019 are selected, and the behavioral consistency of the model is checked. Since thermal power generation refers to power generation using fuel such as coal, oil and gas, the historical data displayed by the total amount of thermal power installed not only includes coal-fired power generation, but there are very few parts of fuel and gas power generation. However, this paper studies the data simulated by coalfired fire power generation, which makes the historical value are large, resulting in a large error rate. By calculation by the error rate in Table 2 , the actual error rate is approximately less than 0.1 , and the behavior consistency of this model is relatively reasonable.

\section{Results and Discussion}

\section{System Simulation and Conclusion Analysis}

In this paper, we have constructed a system dynamics model of the "near-zero emissions" promotion effect of thermal power, and after testing, the model is constructed reasonably. Therefore, Vensim software was used to simulate and promote my country's "nearzero emissions" technology promotion and effects in 2016-2026. Since this section reflects the promotion of "near-zero emissions" technology through the change of the total number of $y$-machine assembly machines, the prediction image of the total amount of $y$-machine assembly machines is selected to show the research results of this article. In this section, without subsidies and with subsidies, three scenarios will be used to simulate and analyze the effect of "near-zero emissions" technology promotion in different scenarios. Scenario 1

Table 3. Simulation data Table1.

\begin{tabular}{|c|c|c|c|}
\hline $\begin{array}{c}\text { Total number of y } \\
\text { machine assembly } \\
\text { machines (MW) }\end{array}$ & Current1 & Current2 & Current3 \\
\hline 2016 & 925097 & 925097 & 925097 \\
\hline 2017 & 857352 & 800245 & 800245 \\
\hline 2018 & 793722 & 685267 & 685267 \\
\hline 2019 & 733908 & 579170 & 579170 \\
\hline 2020 & 677625 & 478336 & 478336 \\
\hline 2021 & 624609 & 386586 & 436784 \\
\hline 2022 & 574610 & 296683 & 397364 \\
\hline 2023 & 527393 & 215338 & 359892 \\
\hline 2024 & 482735 & 136219 & 324194 \\
\hline 2025 & 440428 & 63801 & 290103 \\
\hline 2026 & 400273 & 0 & 257461 \\
\hline
\end{tabular}

* The annual data reflected in the table are the beginning of the year. 


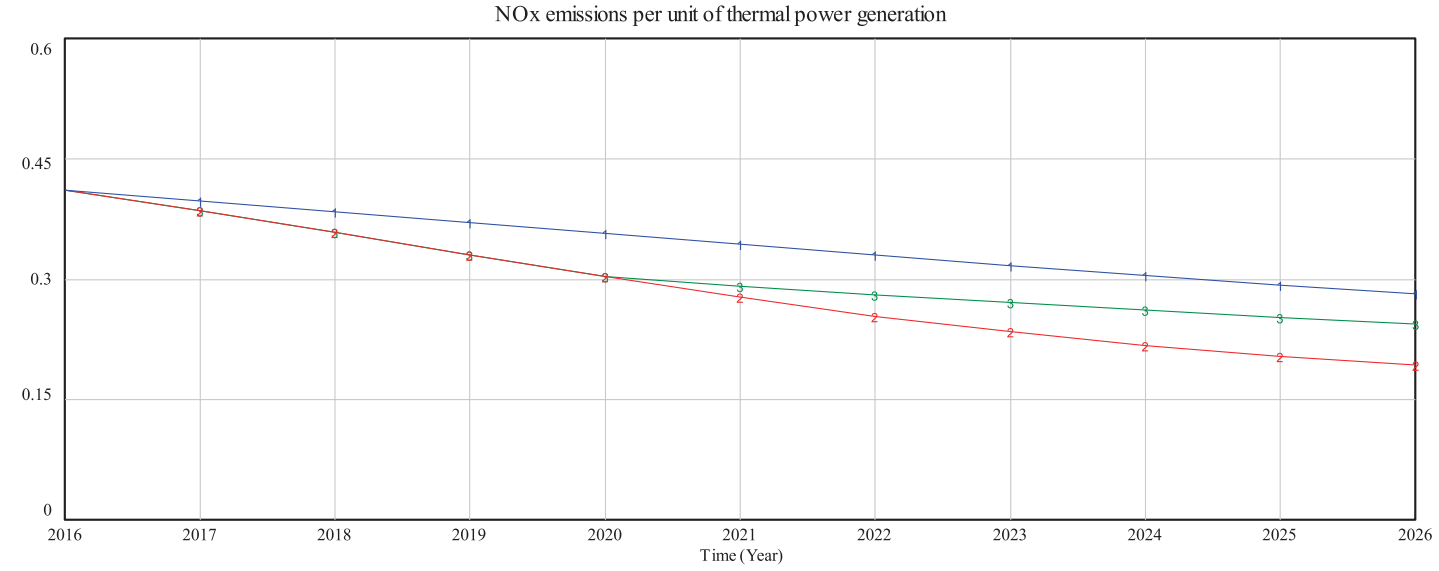

NOx emissions per unit of thermal power generation: Current11

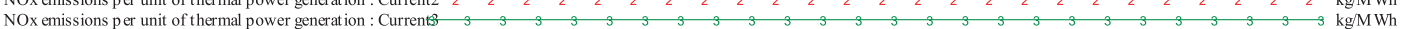

Fig. 5. Scenario simulation comparison of $\mathrm{NO}_{\mathrm{x}}$ emissions of per unit thermal power generation

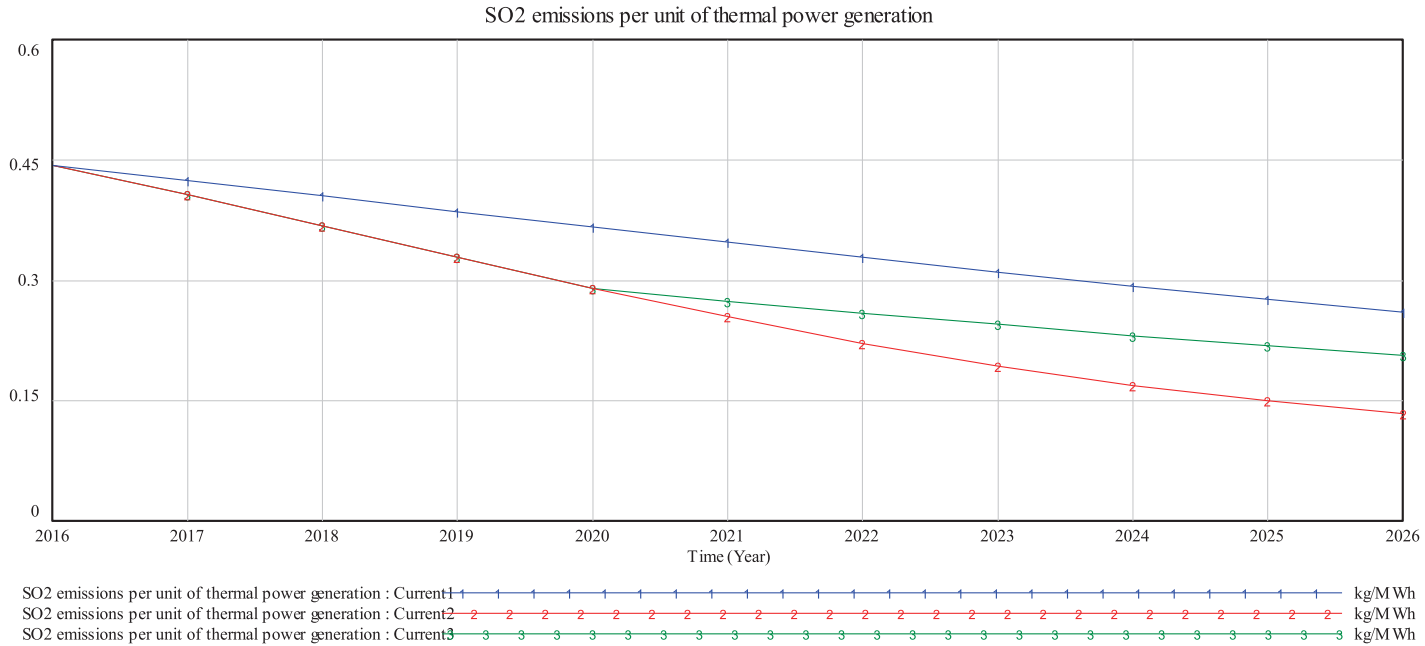

Fig. 6. Scenario simulation comparison of $\mathrm{SO}_{2}$ emissions of per unit thermal power generation.

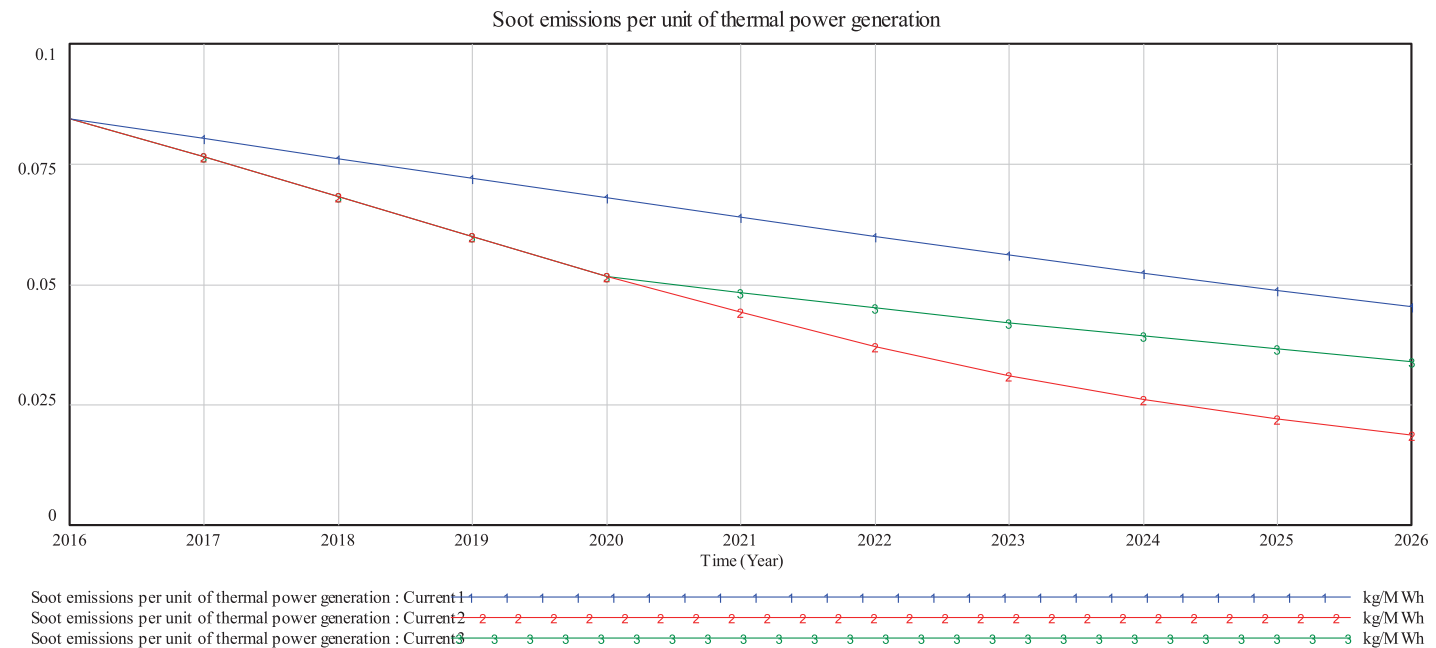

Fig. 7. Scenario simulation comparison of soot emissions of per unit thermal power generation. 
Table 4. Simulation data Table 2.

\begin{tabular}{|c|c|c|c|}
\hline \begin{tabular}{c} 
NO $\begin{array}{c}\mathrm{x} \text { emissions per unit } \\
\text { of thermal power } \\
\text { generation (kg/MWh)* }\end{array}$ \\
\hline 2016
\end{tabular} & Current1 & Current2 & Current3 \\
\hline 2017 & 0.311 & 0.411 & 0.411 \\
\hline 2018 & 0.384 & 0.385 & 0.385 \\
\hline 2019 & 0.370 & 0.330 & 0.330 \\
\hline 2020 & 0.357 & 0.303 & 0.303 \\
\hline 2021 & 0.343 & 0.278 & 0.292 \\
\hline 2022 & 0.330 & 0.254 & 0.281 \\
\hline 2023 & 0.317 & 0.234 & 0.271 \\
\hline 2024 & 0.305 & 0.217 & 0.261 \\
\hline 2025 & 0.293 & 0.204 & 0.252 \\
\hline 2026 & 0.282 & 0.193 & 0.244 \\
\hline
\end{tabular}

* The annual data reflected in the table are the beginning of the year.

Table 5. Simulation data Table 3.

\begin{tabular}{|c|c|c|c|}
\hline $\begin{array}{c}\mathrm{SO}_{2} \text { emissions per unit } \\
\text { of thermal power } \\
\text { generation }(\mathrm{kg} / \mathrm{MWh})\end{array}$ & Current1 & Current2 & Current3 \\
\hline 2016 & 0.443 & 0.443 & 0.443 \\
\hline 2017 & 0.424 & 0.407 & 0.407 \\
\hline 2018 & 0.405 & 0.368 & 0.368 \\
\hline 2019 & 0.386 & 0.329 & 0.329 \\
\hline 2020 & 0.366 & 0.290 & 0.290 \\
\hline 2021 & 0.347 & 0.255 & 0.274 \\
\hline 2022 & 0.329 & 0.221 & 0.259 \\
\hline 2023 & 0.310 & 0.193 & 0.245 \\
\hline 2024 & 0.293 & 0.169 & 0.231 \\
\hline 2025 & 0.276 & 0.150 & 0.219 \\
\hline 2026 & 0.260 & 0.134 & 0.207 \\
\hline
\end{tabular}

* The annual data reflected in the table are the beginning of the year.

(Current1) refers to the promotion effect of "near-zero emissions" technology without subsidies in 2016-2026; Scenario 2 (Current2) refers to the situation where the country adopts the current subsidies from the beginning of the formal implementation of subsidies in early 2016 until 2026 Next, the promotion effect of "near-zero emission" technology; Scenario 3 (Current3) refers to the promotion effect of "near-zero emission" technology when the current subsidies are implemented from 2016 to 2020 and no subsidies will be provided from the beginning of 2020 .
Table 6. Simulation data Table 4.

\begin{tabular}{|c|c|c|c|}
\hline $\begin{array}{c}\text { Soot emissions per } \\
\text { unit of thermal power } \\
\text { generation (kg/MWh)* }\end{array}$ & Current1 & Current2 & Current3 \\
\hline 2016 & 0.084 & 0.084 & 0.084 \\
\hline 2017 & 0.080 & 0.077 & 0.077 \\
\hline 2018 & 0.076 & 0.068 & 0.068 \\
\hline 2019 & 0.072 & 0.060 & 0.060 \\
\hline 2020 & 0.068 & 0.052 & 0.052 \\
\hline 2021 & 0.064 & 0.044 & 0.048 \\
\hline 2022 & 0.060 & 0.037 & 0.045 \\
\hline 2023 & 0.056 & 0.031 & 0.042 \\
\hline 2024 & 0.052 & 0.026 & 0.039 \\
\hline 2025 & 0.049 & 0.022 & 0.037 \\
\hline 2026 & 0.045 & 0.019 & 0.034 \\
\hline
\end{tabular}

* The annual data reflected in the table are the beginning of the year.

By analyzing the changes in the total number of $y$-machine assembly machines, and with or without subsidies, there are three scenarios for predicting the effect of my country's "near-zero emissions" technology promotion, as shown in Fig.4. And the simulation data for 2016-2026 correspond- ing to the above graph is shown in Table 3 below.

By analyzing Fig. 4 and Table 3, it is found that the changes in the total number of y-machine assembly machines reflect the transformation of the "near-zero emission" unit, and then we can analyze the promotion effect of the "near-zero emission" technology. Comparing Current1 and Current2, it is found that the subsidies have promoted the promotion of "nearzero emission" technology since the beginning of 2016, and in early 2026, China's thermal power units will all complete the "near-zero emission" transformation. Comparing Current 2 and Current3, it is found that if the subsidy for the "near-zero emission" technology is cancelled in early 2020, China's thermal power units will not be able to complete the transformation in early 2026.

By analyzing the changes in the power consumption of three pollutants such as soot, $\mathrm{SO}_{2}$ and $\mathrm{NO}_{\mathrm{x}}$ in the model, the effect of "near-zero emission" technology on the emission of thermal power atmospheric pollutants is studied in three scenarios, as shown in Fig. 5 to Fig. 7. And the simulation data for 2016-2026 corresponding to the above graph is shown in Table 4 to Table 6 below.

According to Fig. 5 to Fig.7 and Tables 4 to Tables 6, comparing Current1 and Current2, it is found that subsidies starting from 2016, not only has a good role in the application of "near-zero emissions" technology, but also contribute to better control of thermal power atmospheric pollutant emissions. On 
the basis of simulation, after calculation, with the data of the main air pollutant power emissions of thermal power in China in early 2015 (smoke power discharge $0.23 \mathrm{~g} / \mathrm{kWh}, \mathrm{SO}_{2}$ power discharge $1.47 \mathrm{~g} / \mathrm{kWh}, \mathrm{NO}_{\mathrm{x}}$ power discharge $1.47 \mathrm{~g} / \mathrm{kWh}$ ) Compared with the subsidies, from the beginning of 2016 to the beginning of 2026, the cumulative reduction of sulfur dioxide emissions by about 15.13 million tons, nitrogen oxide emissions by about 15.13 million tons, and soot emissions by about 2.37 million tons. Comparing Current 2 and Current 3 , it is found that if China cancels the subsidy for "near-zero emissions" transformation of thermal power since the beginning of 2020, the three major pollutants of thermal power in China will not reach the "near-zero emissions" standard limit in early 2026; if After 2020, China will continue to provide a subsidy of 0.01 yuan $/ \mathrm{kWh}$ for "near-zero emission" technology. In early 2026, China's thermal power "near-zero emission" technical transformation will be basically completed. At the same time, the three major pollutants of thermal power will be discharged. It will also reach the "near-zero emission" standard limit.

\section{Conclusions}

This paper uses the system dynamics method to construct the "near-zero emission" promotion effect model. We also set up three subsystems such as costprofit subsystem, investment development subsystem, and environmental effect subsystem in the model. Finally this paper simulates and analyzes promotion effect of the "near-zero emission" under different scenarios. Through the above simulation analysis, the following conclusions are drawn:

(1) The subsidy policy implemented by the country since 2016 has played a very good role in promoting the "near-zero emission" of thermal power; in 2020 and after, the 0.01 yuan power subsidy will continue to be used, and my country's thermal power units will be completely renovated in early 2026. If the "nearzero emissions" subsidy for thermal power is cancelled from the beginning of 2020, then as of the beginning of 2026 , there will be approximately $28 \%$ of the stock thermal power units (based on the installed thermal power capacity in early 2016 as the base) that cannot achieve the transformation of "near-zero emissions".

(2) In the case of subsidies, the "near-zero emissions" of thermal power has played a better role in reducing air pollutants. Compared with the case without subsidies, from the beginning of 2016 to the beginning of 2026, the cumulative amount of sulfur dioxide emissions can be reduced by about 15.13 million Tons, reducing nitrogen oxide emissions by about 15.13 million tons, and reducing soot emissions by about 2.37 million tons. At the same time, by the beginning of 2026, the emissions of soot, $\mathrm{SO}_{2}$ and $\mathrm{NO}_{\mathrm{x}}$ in the thermal power industry will fully reach the "near-zero emission" standard.
(3) In the case of subsidies, by the beginning of 2022 , about $68 \%$ of the stock thermal power units have implemented "near-zero emission". From the perspective of rewarding good and punishing inferiorities, and setting a reasonable policy window period, subsidies should not be subsidized for "near-zero emission" retrofit projects implemented after the beginning of 2022.

\section{Acknowledgements}

The authors thank the Chinese coal-fired power plants for their support during the survey.

\section{Conflict of Interest}

The authors declare no conflict of interest.

\section{References}

1. CHEN Y.B., ZHANG Y., LING W. Practice on Ultra-low Emission and Energy Efficient Technologies in Coal-fired Power Plants.Frontiers of Engineering Management, 3 (04), 377, 2016.

2. LIU J., WANG J.W., CHENG J., ZHANG Y.S., WANG T., PAN W.P. Distribution and emission of speciated volatile organic compounds from a coal-fired power plant with ultra-low emission technologies. J Clean Prod, 264, 2020.

3. SI T., WANG C.B., LIU R.Q., GUO Y.S., YUE S., REN Y.J. Multi-criteria com-prehensive energy efficiency assess-ment based on fuzzy-AHP method: A case study of post-treatment technologies for coal-fired units. Energy, 200, 2020.

4. YANG Z.D., JI P.D., LI Q.Y., JIANG Y., ZHENGC.H., WANG Y., GAOX., LIN R.Y. Comprehensive understanding of $\mathrm{SO}_{3}$ effects on synergies among air pollution control devices in ultra-low emission power plants burning high-sulfur coal. J Clean Prod, 239, 2019.

5. CHEN X.J., LIU Q.Z., SHENG T., LI F., XU Z.F., HAN D.M., ZHANG X.F., HUANG X.Q, FU Q.Y., CHENG J.P. A high temporal-spatial emission inventory and updated emission factors for coal-fired power plants in Shanghai, China. SCI TOTAL ENVIRON, 688, 2019.

6. WEN M.N., WU Q.R., LI G.L., WANG S.X., LI Z.J., TANG Y., XU L.W., LIU T.H. Impact of ultra-low emission technology retrofit on the mercury emissions and crossmedia transfer in coal-fired power plants. J HAZARD MATER, 396, 2020.

7. ZHANG L., YUAN G.C., LI S.Y. Selection of ultra-low emission transformation scheme for 300MW CFB unit desulphurization system. IOP Conference Series: Earth and Environmental Science, 227 (4), 2019.

8. WU D., MA X.Z., ZHANG S.Q. Integrating synergistic effects of air pollution control technologies: More costeffective approach in the coal-fired sector in China. Journal of Cleaner Production, 199, 1035, 2018.

9. LI L., HONG X.F., WANG J. Evaluating the impact of clean energy consumption and factor allocation on China's air pollution. A spatial econometric approach. Energy, 195, 2019. 
10. GUO X.P., REN D.F., GUO X.D. A system dynamics model of China's electric power structure adjustment with constraints of PM10 emission reduction. Environ Sci Pollut R, 25 (18), 2018.

11. WANG G., DENG J.G., ZHANG Y., QIANG Z., DUAN L., HAO J.M., JIANG J.K. Air pollutant emissions from coal-fired power plants in China over the past two decades. Sci Total Environ, 741, 2020.

12. HUANG Y.S., WANG H.W., LIU S.J. Research on "NearZero Emission" Technological Innovation Diffusion Based on Coevolutionary Game Appro-ach.Department of Economics and Management, 23, 2019.

13. YU X.Y., WU Z.M., WANG Q.W., SANG X.Z., ZHOU D.Q. Exploring the investment strategy of power enterprises under the nationwide carbon emissions trading mechanism, A scenario-based system dynamics approach. Energ Policy, 140,2020.

14. GONZÁLEZ-GARRIDO A., GAZTAÑAGA H., SAEZDE-IBARRA A., MILO A., EGUIA P. Electricity and reserve market bidding strategy including sizing evaluation and a novel renewable complementarity-based centralized control for storage lifetime enhancement. Appl Energ, 262, 2020.

15. YIN L.B., LIAO Y.F., LIU G.C., LIU Z.C., YU Z.S., GUO S.D., MA X.Q. Comparative analysis of gas and coal-fired power generation in ultra-low emission condition using life cycle assessment (LCA). IOP Conference Series, Materials Science and Engineering, 199 (1), 2017.

16. LI Y., LI H.X., WANG B., ZHOU M., JIN M. Multiobjective unit commitment optimization with ultra-low emissions under stochastic and fuzzy uncertainties. Int $\mathbf{J}$ Mach Learn Cyb, 6 (02), 45, 2020.

17. ZHANG M., LV T., ZHAO Y., PAN J. Effectiveness of clean development policies on coal-fired power generation, an empirical study in China. Environmental ence and Pollution Research. 6 (07), 1, 2016.
18. CUI L., LI Y., TANG Y.Z., SHI Y.F., WANG Q.S., YUAN X.L., KELLETT J. Integrated assessment of the environmental and economic effects of an ultra-clean flue gas treatment process in coal-fired power plant. J Clean Prod, 199, 359, 2018.

19. JEONG S.J., KIM K.S., PARK J.W., LIM D.S., LEE S.M. Economic comparison between coal-fired and liquefied natural gas combined cycle power plants considering carbon tax, Korean case. Energy, 33 (8), 2008.

20. WANG Y.P., YAN W.L., KOMONPIPAT S. How does the capacity utilization of thermal power generation affect pollutant emissions? Evidence from the panel data of China's provinces. Energ Policy, 132, 2019.

21. MAQHUZU A.B., YOSHIKAWA K., TAKAHASHI F. The effect of coal alternative fuel from municipal solid wastes employing hydrothermal carbonization on atmospheric pollutant emissions in Zimbabwe. SCI TOTAL ENVIRON, 668, 2019.

22. KIM G.E., LEE H.J., YOO S.H. Willingness to Pay for Substituting Coal with Natural Gas-Based Combined Heat and Power in South Korea, A View from Air Pollutants Emissions Mitigation. Sustainability-Basel, 10 (5), 2018.

23. LIU X., ZHU A.J., WANG N., GUO S., TIAN C., JIN Y.G., JIANG Z.P. Comparative analysis of the influence of pulverized coal-fired boiler pollutant emission before and after retrofitting on air distribution device. IOP Conference Series, Earth and Environmental Science, 227 (3), 2019.

24. KONG R., XUE F.F., WANG J., ZHAI H.Y., ZHAO L.N. Research on Mineral Resources and Environment of Salt Lakes in Qinghai Province based on System Dynamics Theory. Resour Policy, 52, 19, 2017.

25. CUI L.M., MENG L.X., YUAN H. Ultra-low emission retrofit and its impact on power supply cost. Thermal Power Generation, 46 (06), 119, 2017. 